\title{
Employing Nanoscale Surface Morphologies to Improve Interfacial Adhesion between Solid Electrolytes and Li Ion Battery Cathodes
}

Xin Su ${ }^{1, \mathrm{a}}$, Teng Zhang ${ }^{1, \mathrm{~b}}$, ,Xin Liang ${ }^{1, \mathrm{c}}$, Huajian Gao ${ }^{1, \mathrm{~d}}$, Brian W. Sheldon ${ }^{1, \mathrm{e}^{*}}$

${ }^{1}$ School of Engineering, Brown University, Providence, RI 02912, USA.

a suxin81@gmail.com, b teng_zhang@brown.edu, c liangxin matersci@126.com, huajian_gao@brown.edu, ${ }^{\text {e }}$ brian_sheldon@brown.edu.

* Corresponding author, B.W. Sheldon.

Address: 182 Hope Street, Providence, RI 02912, USA

Tel: +1 (401) 8632866

Email: brian_sheldon@brown.edu 
Abstract

Solid state Li ion batteries are particularly susceptible to deleterious mechanical responses at interfaces, because the electrochemically driven volume changes must be accommodated by deformation of the solid electrolyte. In the current study, this was investigated with PEO electrolyte and $\mathrm{V}_{2} \mathrm{O}_{5}$ electrodes, using different morphologies (e.g. patterned films, plasma roughened surfaces, etc). Detailed finite element modeling of the experimental configuration was also used to analyze the results. Methods for improving the adhesion of this critical interface were also demonstrated. Relatively small improvements were attributed to plasma roughening. However, the introduction of large, thin sheets of material normal to the primary decohesion surface lead to unexpected large increases in the adhesive energy. For example, with patterned islands that were $800 \mathrm{~nm}$ tall, the increase in adhesion was approximately 8 times larger than the corresponding surface area increase. A finite element simulation of the decohesion process shows good agreement with the experimental values. Based on this analysis, it appears that thin elastic sheets in a much softer matrix can reduce stresses at the delamination front. This shielding effect provides a novel approach for improving the failure resistance of PEO electrolyte/ $/ \mathrm{V}_{2} \mathrm{O}_{5}$ interfaces in solid state batteries.

Keywords: PEO electrolyte; solid state lithium battery; $\mathrm{V}_{2} \mathrm{O}_{5}$; interface 


\section{Introduction}

Solid state electrolytes in Li ion batteries are attractive for many applications because of their higher thermal and electrochemical stability compared to the liquid electrolytes that are widely used.[1, 2] Polymer electrolytes offer important advantages such as mechanical flexibility (i.e., low elastic modulus), low costs, etc.[3-12] Poly ethylene oxide (PEO) has been widely investigated as a promising electrolyte for solid state batteries. Here, the electrochemical and mechanical properties of the interface between PEO and electrode materials are expected to be critical.[6-9, 13, 14] In particular, weak adhesion at these interfaces is likely to be problematic, however, systematic investigations of this behavior have not been previously reported.

Here we present a systematic study of adhesion between PEO electrolytes and vanadium oxide films. Extensive research has been conducted on developing vanadium oxides as cathode materials for lithium ion batteries.[15-19] For the current experiments, one important reason for using vanadium oxide as a model cathode is that it is relatively easy to produce in thin film form, compared to other multi-cation cathode materials. Lithium polymer batteries with vanadium pentoxide cathodes are also of interest for applications in electric vehicles, to reduce the safety risks associated with liquid electrolytes.[20, 21]

The baseline measurements that we report for PEO on vanadium oxide show relatively low adhesion energies between these materials. This weak interface with PEO is a serious issue, particularly because the cathode material undergoes substantial volume changes during Li insertion and removal. The impact of the resulting stresses 
at electrolyte / electrode interfaces requires careful consideration. With this in mind, both experiments and finite element method (FEM) simulations were used to understand the impact of surface morphology. It is well established that surface morphology can substantially impact adhesion of bimaterial interfaces.[22-27] A relatively simple example is a rougher surface that increases adhesion by increasing the effective interfacial contact area. Mechanisms that can lead to larger improvements are desirable, and one of the key finding in the work report here is that thin layers oriented perpendicular to the primary delamination front can substantially increase the adhesion energy. Overall, our results demonstrate that adjusting surface morphology of the electrode is an effective approach to improving the mechanical properties of the interface in vanadium oxide/PEO electrolyte system in solid-state lithium batteries.

\section{Experimental and Simulation Section:}

\section{Preparation of the $\mathrm{V}_{2} \mathrm{O}_{5}$ smooth film and patterned film}

The current collector $100 \mathrm{~nm} \mathrm{Ti} / 100 \mathrm{~nm} \mathrm{Au}$ was first deposited on quartz substrates (1 inch in diameter and $250 \mu \mathrm{m}$ in thickness, University wafer) by electron-beam evaporation. The $50 \mathrm{~nm} \mathrm{~V}_{2} \mathrm{O}_{5}$ film was then deposited on the current collector by magnetic sputtering (Lesker lab 18) with a vanadium target in an atmosphere of $90 \% \mathrm{Ar}$ and $10 \% \mathrm{O}_{2}$.

The patterned films were developed through a standard lithographic process. Photoresist (AZ 5214 E) was spin coated on the current collector at a rate of $1500 \mathrm{rpm}$ for $45 \mathrm{~s}$. Then the photoresist was baked at $110{ }^{\circ} \mathrm{C}$ for $60 \mathrm{~s}$. After baking, the 
photoresist was exposed with $365 \mathrm{~nm}$ wavelength $\left(80 \mathrm{~mJ} / \mathrm{cm}^{2}\right.$ dose $)$, using the 2000 LPI fine Ni Mesh as the mask (with patterned size of $7 \mu \mathrm{m} \times 7 \mu \mathrm{m}$ ). The sample was developed in AZ 300 MIF for 70 s. Finally the $\mathrm{V}_{2} \mathrm{O}_{5}$ patterned films with islands of different heights were created by magnetic sputtering and removing the photo-patterned.

\section{$\mathrm{O}_{2}$ plasma treatment and annealing process}

The as deposited vanadium oxide film were treated by oxygen plasma at $200 \mathrm{~W}$ for 5 minutes and annealed at $400{ }^{\circ} \mathrm{C}$ in air for $8 \mathrm{~h}$ to see the impacts of plasma and annealing treatments on the adhesive energy between PEO electrolyte and the film. The as-deposited vanadium oxide patterned films were also treated by two approaches to see their impacts on the adhesion energy between the PEO electrolyte and the patterned films.

\section{PEO electrolyte films}

The $1.67 \mathrm{~g}$ PEO electrolyte (Medtronic Inc.) was firstly dissolved in $10 \mathrm{~g}$ acetonitrile (Sigma-Aldrich). The solution was spin coated on $\mathrm{V}_{2} \mathrm{O}_{5}$ smooth films and patterned films at a rate of $700 \mathrm{rpm}$ for $90 \mathrm{~s}$. After drying at RT, the $5.9 \mu \mathrm{m}$ PEO electrolyte films were formed and attached to the $\mathrm{V}_{2} \mathrm{O}_{5}$ films.

\section{Peeling test}


The PEO electrolyte film, which was loaded on vanadium oxide films, was peeled off by Instron 5882 with the load cell of $500 \mathrm{~N}$ and the force accuracy of $1 \mathrm{mN}$. The part of PEO electrolyte film was firstly manually peeled off and attached to an adhesive tape with quick dry glue and the remaining of PEO electrolyte film was peeled off at a constant rate of $0.7 \mathrm{~mm} /$ minute. The custom design is developed to maintain a peeling angle $\sim 90^{\circ}$ between force direction and interface during the peeling test. The force needed to peel the PEO electrolyte film from the vanadium oxide film was recorded for calculating the adhesion energy between PEO electrolyte and the vanadium oxide films.

\section{Characterization of $\mathrm{V}_{2} \mathrm{O}_{5}$ films'surface morphology and $\mathrm{Au}$ film}

The surface morphologies of $\mathrm{V}_{2} \mathrm{O}_{5}$ smooth films and patterned films before/after annealing and plasma treatment were characterized by scanning electron microscopy (SEM, Zeiss LEO-1530 VP at $10 \mathrm{kV}$ ) and atomic force microscopy under tapping mode (AFM, Asylum MFP-3D Origin AFM). The crystal structure of $\mathrm{V}_{2} \mathrm{O}_{5}$ smooth film before/after annealing was characterized by X-ray Diffraction (XRD Siemens D-5000) from $10^{\circ}$ to $90^{\circ}$ at glancing angle of $1^{\circ}$ and scan rate of $0.02^{\circ} / \mathrm{s}$. The surface modification on Au film during the photolithography process was characterized by X-ray Photoelectron Spectra (XPS, Physical Electronics Quantum 2000) at $100 \mathrm{~W}$ and $18 \mathrm{kV}$. 
The Young's modulus of the spin coated PEO electrolyte on $\mathrm{V}_{2} \mathrm{O}_{5}$ was determined with a Triboindenter (Hysitron), using Berkovich indenter, the load control mode, the maximum load of $10 \mu \mathrm{N}$ and loading/unloading rate of $4 \mu \mathrm{N} / \mathrm{s}$. The indentation tests were performed with/without 2 s pause. The Young's modulus were similar with/without pause, which were obtained from Triboscan software Analysis of Hysitron TI950. The shape of the indentation curves shows that there is some rate dependent deformation of the PEO (Figure S5). This was not accounted for in the initial simulations that are reported here.

\section{Finite Element Model}

The system of PEO attached to the flat and patterned $\mathrm{V}_{2} \mathrm{O}_{5}$ substrates was simulated with a finite element model (FEM). In the numerical simulation, a three-dimensional (3D) strip and a thin plate with symmetry boundary condition on the lateral sides are used to represent the unit cell of PEO and $\mathrm{V}_{2} \mathrm{O}_{5}$ substrate with periodical islands, respectively. Since the fully 3D FEM simulations for the PEO-island system will lead to large scale computations, here we adopt a smaller square island with width of $2 \mu \mathrm{m}$ (shown in Figure S4 (a)), while keep the area ratio of the island the same as the experimental set up ( 25\%). A symmetry boundary condition is applied to the right end surface of both the PEO and $\mathrm{V}_{2} \mathrm{O}_{5}$ to prevent crack nucleation from the right end of the strip due to the modulus mismatch. These boundaries will lead to $\varepsilon_{z z}=0$ and a close zero value of $\varepsilon_{x x}$ at the position far away from the interfacial crack tip. The composite structure contains an initial edge crack 
along the interface between PEO and $\mathrm{V}_{2} \mathrm{O}_{5}$. A constant velocity loading is applied on the top surface of the PEO strip where a very low loading rate is adopted to ensure a quasistatic process. All the 3D FEM simulations are performed with ABAQUS/Explicit. Both the PEO and $\mathrm{V}_{2} \mathrm{O}_{5}$ are modeled using 8-node linear brick elements with incompatible modes (C3D8I). The PEO and $\mathrm{V}_{2} \mathrm{O}_{5}$ are modeled as linear elastic materials with geometrically nonlinear deformation, Poisson's ratio of 0.3 , and Young's modulus of $0.85 \mathrm{GPa}$ and $100 \mathrm{GPa}$, respectively. The adhesion between PEO and $\mathrm{V}_{2} \mathrm{O}_{5}$ substrate is described with cohesive elements implemented in ABAQUS. A triangular softening cohesive law with a maximum strength and separation distance at $85 \mathrm{MPa}$ and $80 \mathrm{~nm}$ is used to describe the interaction between PEO and $\mathrm{V}_{2} \mathrm{O}_{5}$ substrate for both flat and rough interface (illustrated in Figure S4 (b)). The damage initiation of cohesive interaction is described with quadratic nominal stress criterion (shown in Equation S2) so that the decohesion in normal and shear directions follow the same traction-separation law and will equally contribute to the failure under mix mode loading.

\section{Adhesion Results}

Figure 1 (a) and (b) show the $90^{\circ}$ peeling test results for PEO removal from the vanadium oxide film at rates of $0.7 \mathrm{~mm} /$ minute and $1.4 \mathrm{~mm} /$ minute. These results indicate that the peeling rate has no impact on the applied peeling force. This constant peeling force demonstrates the uniformity of the interface between $\mathrm{V}_{2} \mathrm{O}_{5}$ film and PEO electrolyte. Here the adhesion energy $3.2 \mathrm{~J} / \mathrm{m}^{2}$ of PEO to the $\mathrm{V}_{2} \mathrm{O}_{5}$ is calculated 
from the measured peeling force. As shown in Figure 2 (a), (b), (c), the surface morphology of the smooth $\mathrm{V}_{2} \mathrm{O}_{5}$ film is similar before/after the oxygen plasma treatment but becomes rougher after annealing at $400^{\circ} \mathrm{C}$ in air for $8 \mathrm{~h}$. The corresponding adhesion energies of these surface morphologies are listed in Table 1, in rows 2 (untreated), 3 (after plasma), and 7 (after annealing).

The adhesion energies are similar before/after plasma treatment but slightly increased from $3.2 \mathrm{~J} / \mathrm{m}^{2}$ to $3.8 \mathrm{~J} / \mathrm{m}^{2}$ when the surface became rougher after annealing. According to the XRD of the $\mathrm{V}_{2} \mathrm{O}_{5}$ film before/after annealing in Figure $\mathrm{S} 1$ (a) and (b), the as-deposited film is amorphous but it starts to crystalize during annealing at $400{ }^{\circ} \mathrm{C}$ for $8 \mathrm{~h}$ in air. This change likely makes the surface rougher than the original surface.

To further explore the impact of the $\mathrm{V}_{2} \mathrm{O}_{5}$ film surface morphology on its adhesion to PEO, patterned films with islands of different heights were developed on $\mathrm{Au}$ current collectors via a photolithography process. To properly interpret the measurements with these patterned films, adhesion between theAu surface and the PEO electrolyte must be evaluated. This was accomplished by first exposing the Au films to the full photolithography process without depositing the $\mathrm{V}_{2} \mathrm{O}_{5}$ islands. This treatment substantially improves the adhesion energy by this surface modification of the Au current collector during the photolithography process (seen in Figures S2). However, adhesion returns to the original value after the functional groups have been removed by $\mathrm{O}_{2}$ plasma (seen in Figure $\mathrm{S} 2$ (d)). The corresponding surface modification of the Au films during photolithography was also confirmed by XPS (see 
Figure S3 (a) and (b)).

Adhesion results with a series of $\mathrm{V}_{2} \mathrm{O}_{5}$ patterned films with islands of different heights $(28 \mathrm{~nm}, 50 \mathrm{~nm}, 100 \mathrm{~nm}, 200 \mathrm{~nm}, 400 \mathrm{~nm}, 800 \mathrm{~nm})$ are reported in Table 1. Simple estimates of the expected increase in adhesion due to the interfacial area between the PEO electrolyte and the patterned films are calculated by:

$$
\mathrm{J}_{\text {estimated }}=\mathrm{J}_{\text {unit }} * \mathrm{~A}_{\text {patterned }}=\mathrm{J}_{\text {unit }} * \mathrm{~A}_{\text {smooth }}\left(1+\mathrm{A}_{\text {increase }} / \mathrm{A}_{\text {smooth }}\right)
$$

Here $\mathrm{J}_{\text {estimated }}$ is the estimated adhesion energy of PEO electrolyte to the patterned films; $J_{\text {unit }}$ is the adhesion energy of PEO electrolyte to unit area of $\mathrm{V}_{2} \mathrm{O}_{5}$ film; $A_{\text {patterned }}$ is the total surface area of the patterned film; $\mathrm{A}_{\text {smooth }}$ is the total surface area of the smooth film; $A_{\text {increase }}$ is the increase in area of the patterned film over the smooth film due to the side walls of the islands. According to Equation 1, the estimated adhesion energies of the PEO electrolyte to the patterned films are only slightly higher than that of the smooth films. This reflects the relatively small increase in area associated with these islands. In contrast to this, the corresponding adhesion energies obtained by peeling tests (Table 1) are much larger than the estimated values. For island heights of $28 \mathrm{~nm}$ to $400 \mathrm{~nm}$, the adhesion energies are $4.9 \mathrm{~J} / \mathrm{m}^{2}$ to $6.1 \mathrm{~J} / \mathrm{m}^{2}$ (after accounting for the Au portion of the substrate after $\mathrm{O}_{2}$ plasma treatments). Taking the patterned films with $400 \mathrm{~nm}$ islands as an example, the increase of adhesion energy due to the roughness is $2.5 \mathrm{~J} / \mathrm{m}^{2}$, which is about 12 times of that due to increasing the surface area $\left(0.2 \mathrm{~J} / \mathrm{m}^{2}\right)$. Estimates based on the total surface area of the electrodes were made and shown in row $5^{\text {th }}$ (after plasma), and $9^{\text {th }}$ (after annealing)

A likely explanation for the large increases in adhesion are the sharp edges on 
the islands seen in Figures (a) - (f) (these edges are especially severe when the height is $800 \mathrm{~nm}$, as shown in Figure 3 (f)). In the AFM image and the cross sectional profile of the patterned films with island height of $800 \mathrm{~nm}$ in Figure 4 (a), (b), the large features around the edges of islands are observed. Those morphologies are more clearly demonstrated in 3D images of the patterned film before/after the plasma and annealing. Because the sharp edges are very thin (on the order of a hundred $\mathrm{nm}$ in thickness), they can undergo substantial elastic bending deformation during the peeling test. This can hinder the release of elastic energy during the separating test to improve the adhesion energy between the PEO electrolyte and patterned film. The results of our peeling test support this hypothesis. At the edge height of $800 \mathrm{~nm}$, the adhesion energy of PEO electrolyte jumps to $8 \mathrm{~J} / \mathrm{m}^{2}$, which is believed to be an integrated result of roughness caused by the height and elastic deformation of the islands' edge. The adhesion energy for islands with height of $800 \mathrm{~nm}$ is 8 times of that due to the increased surface area alone. As shown in Figure 5, the roughness of the electrode caused by the islands can increase the adhesion energy much more than that due to the extra surface generated by the islands.

To provide additional information about the specific contributions from surface modifications and morphology effects, a series of patterned films were annealed at $400{ }^{\circ} \mathrm{C}$ for $8 \mathrm{~h}$ in air. As shown in row 9 of Table 1, the adhesion energies of the PEO electrolyte to these patterned films after annealing are similar to those after the $\mathrm{O}_{2}$ plasma treatment. This provides additional confirmation that our approach has properly accounted for surface modifications to the exposed Au portion of the 
specimens.

\section{Analysis and Discussion}

The corresponding FEM simulations (performed with ABAQUS) were designed to evaluate the impact of surface topography on adhesion energy for the patterned films. Island configurations with/without edges were analyzed (seeFigure S4). For these calculations, only elastic deformation of the polymer was considered (i.e., possible viscoelastic behavior in the polymer was neglected). This assumption is based in part on the results in Figure 1 where the measured adhesion energies do not vary significantly when the peeling rate is changed. This implies that rate dependent flow in the polymer does not alter the measured values (although this observation does not completely preclude effects due to localized plasticity). The elastic properties of the PEO were obtained from direct nanoindentation measurements, which give an estimated Young's modulus of $0.85 \mathrm{GPa}$ for the PEO electrolyte on the $\mathrm{V}_{2} \mathrm{O}_{5}$ films. The adhesion energy is defined as $\Gamma=1 / 2 \bar{E} H \varepsilon_{c}^{2},[28]$ where $H$ is the width of the PEO strip, and $\varepsilon_{c}$ is the critical strain at the point where the PEO and $\mathrm{V}_{2} \mathrm{O}_{5}$ interface fails catastrophically (i.e., the maximum stress in the stress-strain curve (Figure 7 (a)). The elastic constant is given by, $\bar{E}=\frac{E(1-v)}{(1+v)(1-2 v)}$, where $E$ and $v$ are the Young's modulus (measured from nanoindentation in Figure S5) and Poisson's ratio.

To model the sharp edge features on the islands (i.e., observed in the SEM images in Fig. 3 and AFM images in Figure 4), a thin $100 \mathrm{~nm}$ thick edge with half the 
island height was added to the FEM simulation. Here, the interaction between PEO and the island edge is assumed to be the same as that for the PEO and the $\mathrm{V}_{2} \mathrm{O}_{5}$ islands' top surface (i.e., the same cohesive separation law is adopted for the surface-surface interaction of both interfaces). Stress contours for PEO on the patterned films (800 nm height) with/without the extra edge are shown in Figure 6 (a-b) and (c-d). The crack front deflects around the island, which is consistent with the experimental observations and with theoretical predictions and numerical models based on adhesion energies that are relatively low (i.e., compared to the $\mathrm{Au} / \mathrm{V}_{2} \mathrm{O}_{5}$ interface here).[29, 30] It is particularly interesting that the edge feature has an unexpectedly large effect on the interfacial decohesion process. For example, Figure 7 shows comparisons between the failure strains with and without the edge. The strains needed for crack growth without the edge are shown as dotted lines. When the edge feature is present, a significantly higher strain is required to initiate crack growth. The edge also undergoes bending deformation as shown by the compressive stress at the bottom of the edge (illustrated in Figure 6 (b)).

The comparisons between experiments and simulations with/without edge structures are shown in Figure 7 (b). These results confirm that the islands hinder crack propagation at the $\mathrm{PEO} / \mathrm{V}_{2} \mathrm{O}_{5}$ interface and thus increase the adhesion energy. The full set of experiments was fit to this model. The results in Figure 7(b) show that if the edge features are neglected, the model predicts adhesion energy which are substantially lower than those measured. The model accurately predicts the experiments when the edge features are incorporated in the simulation.. 
As illustrated in Figure 7(b), the increase in the island height cannot alone explain the total enhancement in adhesion energy observed in our peeling tests. In addition, our simulations indicate that the adhesion energy remains a roughly constant value for the case with island height greater than $400 \mathrm{~nm}$. In contrast, the FEM simulations show that the proposed surface morphology structure with sharp edges can continue to facilitate adhesion enhancement for the island with height of $1200 \mathrm{~nm}$ (shown in Figure 7 (b)). The adhesion enhancement mechanism can be attributed to the modulation of the crack tip stress field and the elastic energy stored in the thin edge due to the bending deformation. For example, when the islands' height is $800 \mathrm{~nm}$, the adhesion energy of PEO electrolyte to the island with edge is $\sim 3 \mathrm{~J} / \mathrm{m}^{2}$ higher than that without edge. To explore the details of impact of the edge on the adhesion energy, the $800 \mathrm{~nm}$ island with an extra edge in the middle of the island was modeled. The results show that the extra edge in the middle of island does not provide a significant enhancement in the adhesion energy. As shown in Figure S6, the stress generated in PEO electrolyte and $\mathrm{V}_{2} \mathrm{O}_{5}$ patterned film at the failure strain ( 0.056) was concentrated on the first edge, which indicates that the elastic bending deformation mostly happened on the first edge during the peeling process to enhance the adhesion energy. Since the stress field near the interface between the PEO and $\mathrm{V}_{2} \mathrm{O}_{5}$ islands is complicated, further study may be needed to clarify this in the future.

\section{Conclusion}

The adhesion energies of PEO electrolyte to $\mathrm{V}_{2} \mathrm{O}_{5}$ electrode smooth films and 
patterned films have been systematically studied by experiments and FEM simulations. The results demonstrate that surface modification, including roughness associated with the islands themselves and island edges in the patterned films, can greatly enhance the adhesion energy of the interface between the PEO electrolyte and $\mathrm{V}_{2} \mathrm{O}_{5}$ electrode. The roughness of electrode including heights and edges of islands in the patterned films is believed to be the critical factor for improving strength of the interface between the PEO electrolyte and electrode by hindering propagation of cracks and storing the elastic energy. Slightly increasing the roughness by patterned films with islands $800 \mathrm{~nm}$ in height is found to greatly enhance the adhesion energy of PEO electrolyte to electrode, the increase of which by roughness is about 8 times of that by the increase in surface area. This means tuning the electrode's roughness can play a critical role in improving the stability of electrochemical and mechanical properties of solid state lithium batteries.

\section{Acknowledgements}

We gratefully acknowledge support from Medtronic Inc. and NSF (award DMR-0805172). 
Reference:

1. Takada, K., Progress and prospective of solid-state lithium batteries. Acta Materialia, 2013. 61(3): p. 759-770.

2. Seo, I. and S.W. Martin, Fast lithium ion conducting solid state thin-film electrolytes based on lithium thio-germanate materials. Acta Materialia, 2011. 59(4): p. 1839-1846.

3. Wegner, G., Functional polymers. Acta Materialia, 2000. 48(1): p. 253-262.

4. Meyer, W.H., Polymer Electrolytes for Lithium-Ion Batteries. Advanced Materials, 1998. 10(6): p. 439-448.

5. Zhu, Y.S., et al., A trilayer poly(vinylidene fluoride)/polyborate/poly(vinylidene fluoride) gel polymer electrolyte with good performance for lithium ion batteries. Journal of Materials Chemistry A, 2013. 1(26): p. 7790-7797.

6. Lightfoot, P., M.A. Mehta, and P.G. Bruce, CRYSTAL-STRUCTURE OF THE POLYMER ELECTROLYTE POLY(ETHYLENE OXIDE)3LICF3SO3. Science, 1993. 262(5135): p. 883-885.

7. Croce, F., et al., Nanocomposite polymer electrolytes for lithium batteries. Nature, 1998. 394(6692): p. 456-458.

8. MacGlashan, G.S., Y.G. Andreev, and P.G. Bruce, Structure of the polymer electrolyte poly(ethylene oxide)(6): LiAsF6. Nature, 1999. 398(6730): p. 792-794.

9. Christie, A.M., et al., Increasing the conductivity of crystalline polymer electrolytes. Nature, 2005. 433(7021): p. 50-53.

10. Kil, E.H., et al., Imprintable, Bendable, and Shape-Conformable Polymer Electrolytes for Versatile-Shaped Lithium-Ion Batteries. Advanced Materials, 2013. 25(10): p. 1395-1400.

11. Tu, Z.Y., et al., Nanoporous Polymer-Ceramic Composite Electrolytes for Lithium Metal Batteries. Advanced Energy Materials, 2014. 4(2).

12. Zhu, Y.S., et al., A Composite Gel Polymer Electrolyte with High Performance Based on Poly(Vinylidene Fluoride) and Polyborate for Lithium Ion Batteries. Advanced Energy Materials, 2014. 4(1).

13. Lecuyer, M., et al., Structural changes of a Li/S rechargeable cell in Lithium Metal Polymer technology. Journal of Power Sources, 2013. 241: p. 249-254.

14. Angulakhsmi, N., et al., Cycling profile of innovative nanochitin-incorporated poly (ethylene oxide) based electrolytes for lithium batteries. Journal of Power Sources, 2013. 228: p. 294-299.

15. Zhai, T., et al., Centimeter-Long V2O5 Nanowires: From Synthesis to Field-Emission, Electrochemical, Electrical Transport, and Photoconductive Properties. Advanced Materials, 2010. 22(23): p. 2547-2552.

16. Xiong, X.H., et al., Role of V2O5 coating on LiNiO2-based materials for lithium ion battery. Journal of Power Sources, 2014. 245: p. 183-193.

17. Uchaker, E., et al., Enhanced Intercalation Dynamics and Stability of Engineered Micro/Nano-Structured Electrode Materials: Vanadium Oxide 
Mesocrystals. Small, 2013. 9(22): p. 3880-3886.

18. Liu, Y.Y., et al., V2O5 Nano-Electrodes with High Power and Energy Densities for Thin Film Li-Ion Batteries. Advanced Energy Materials, 2011. 1(2): p. 194-202.

19. Pohl, A.H., et al., Oxidation state and local structure of a high-capacity LiF/Fe(V2O5) conversion cathode for Li-ion batteries. Acta Materialia, 2014. 68(15): p. 179-188.

20. Osada, I., et al., Improved lithium-metal/vanadium pentoxide polymer battery incorporating crosslinked ternary polymer electrolyte with $N$-butyl-N-methylpyrrolidinium bis(perfluoromethanesulfonyl)imide. Journal of Power Sources, 2014. 271(0): p. 334-341.

21. Appetecchi, G.B., et al., Investigation on lithium-polymer electrolyte batteries. Journal of Power Sources, 2001. 97-8: p. 790-794.

22. Bietsch, A. and B. Michel, Conformal contact and pattern stability of stamps used for soft lithography. Journal of Applied Physics, 2000. 88(7): p. 4310-4318.

23. Persson, B. and S. Gorb, The effect of surface roughness on the adhesion of elastic plates with application to biological systems. The Journal of chemical physics, 2003. 119(21): p. 11437-11444.

24. Vajpayee, S., et al., Adhesion selectivity using rippled surfaces. Advanced Functional Materials, 2011. 21(3): p. 547-555.

25. Shahsavan, H. and B. Zhao, Conformal adhesion enhancement on biomimetic microstructured surfaces. Langmuir, 2011. 27(12): p. 7732-7742.

26. Singh, A.K., et al., Adhesion of Microchannel-Based Complementary Surfaces. Langmuir, 2012. 28(9): p. 4213-4222.

27. Cordisco, F.A., et al., Toughness of a patterned interface between two elastically dissimilar solids. Engineering Fracture Mechanics, 2012. 96: p. 192-208.

28. Anderson, T.L., Fracture mechanics: fundamentals and applications2005: CRC press.

29. Gao, H. and J.R. Rice, A first-order perturbation analysis of crack trapping by arrays of obstacles. Journal of applied mechanics, 1989. 56(4): p. 828-836.

30. Bower, A. and M. Ortiz, A three-dimensional analysis of crack trapping and bridging by tough particles. Journal of the Mechanics and Physics of Solids, 1991. 39(6): p. 815-858. 
Figures and captions:
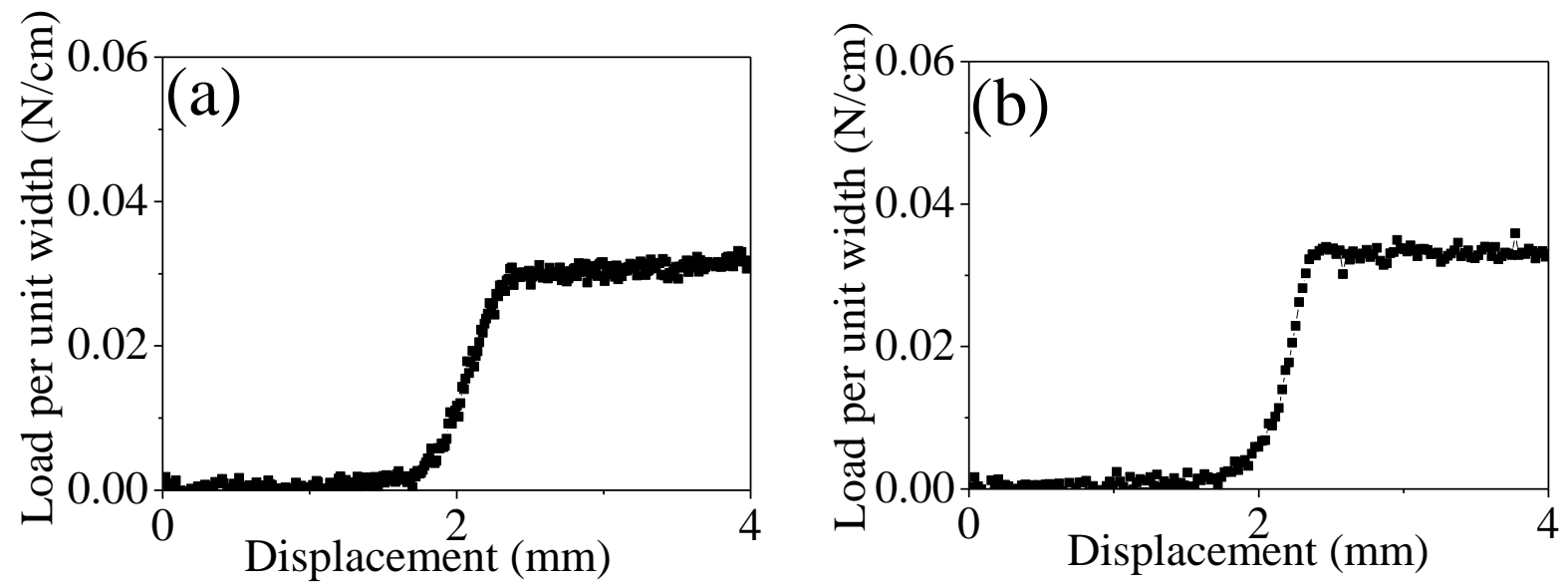

Figure 1. Peeling test of PEO electrolyte on smooth $\mathrm{V}_{2} \mathrm{O}_{5}$ film at peeling rates of $0.7 \mathrm{~mm} /$ minute (a) and $1.4 \mathrm{~mm} /$ minute (b) 

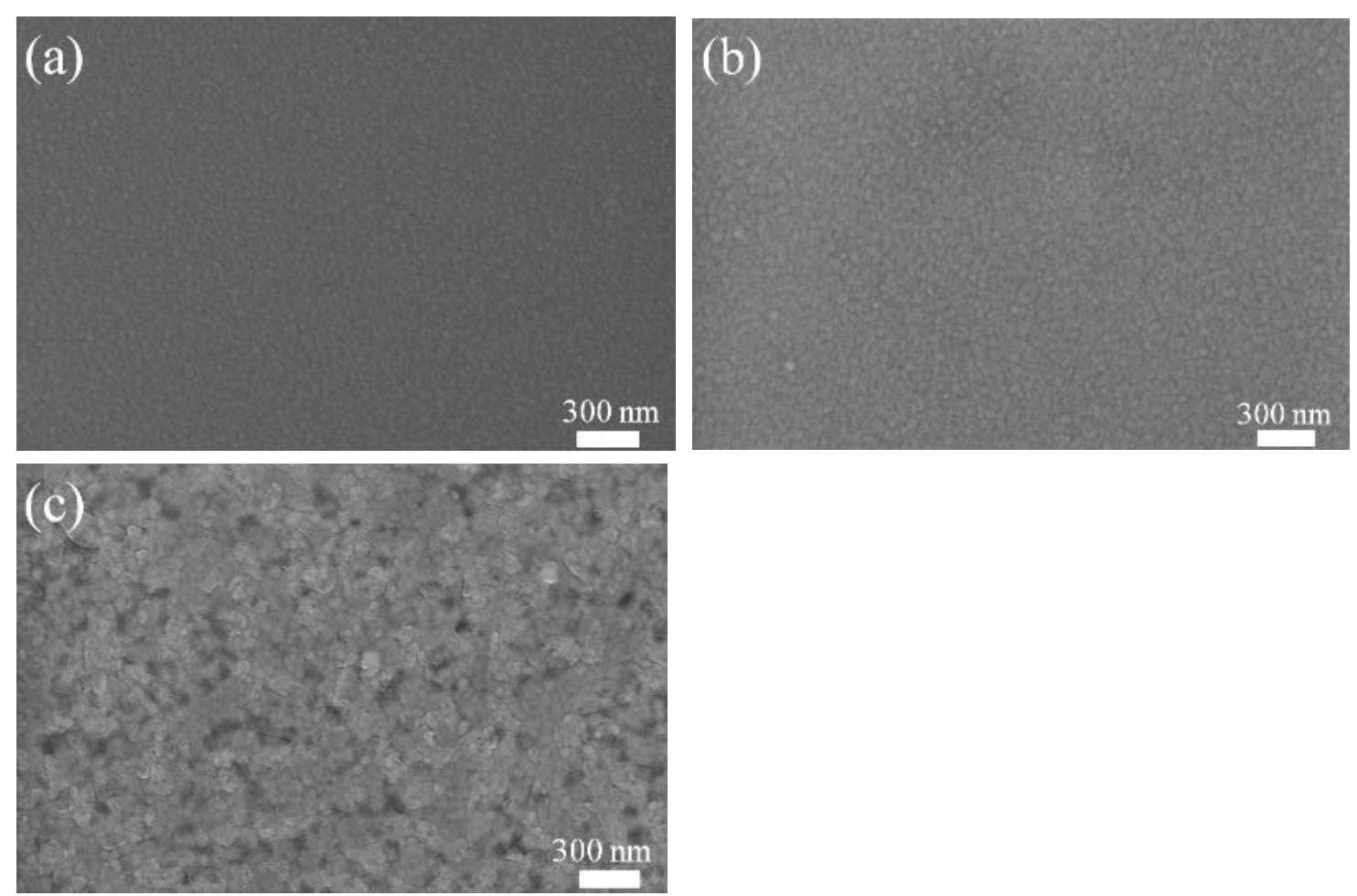

Figure 2. SEM images of the $\mathrm{V}_{2} \mathrm{O}_{5}$ smooth film with thickness of $28 \mathrm{~nm}$ : before (a) and after plasma treatment (b) and annealing (c) 

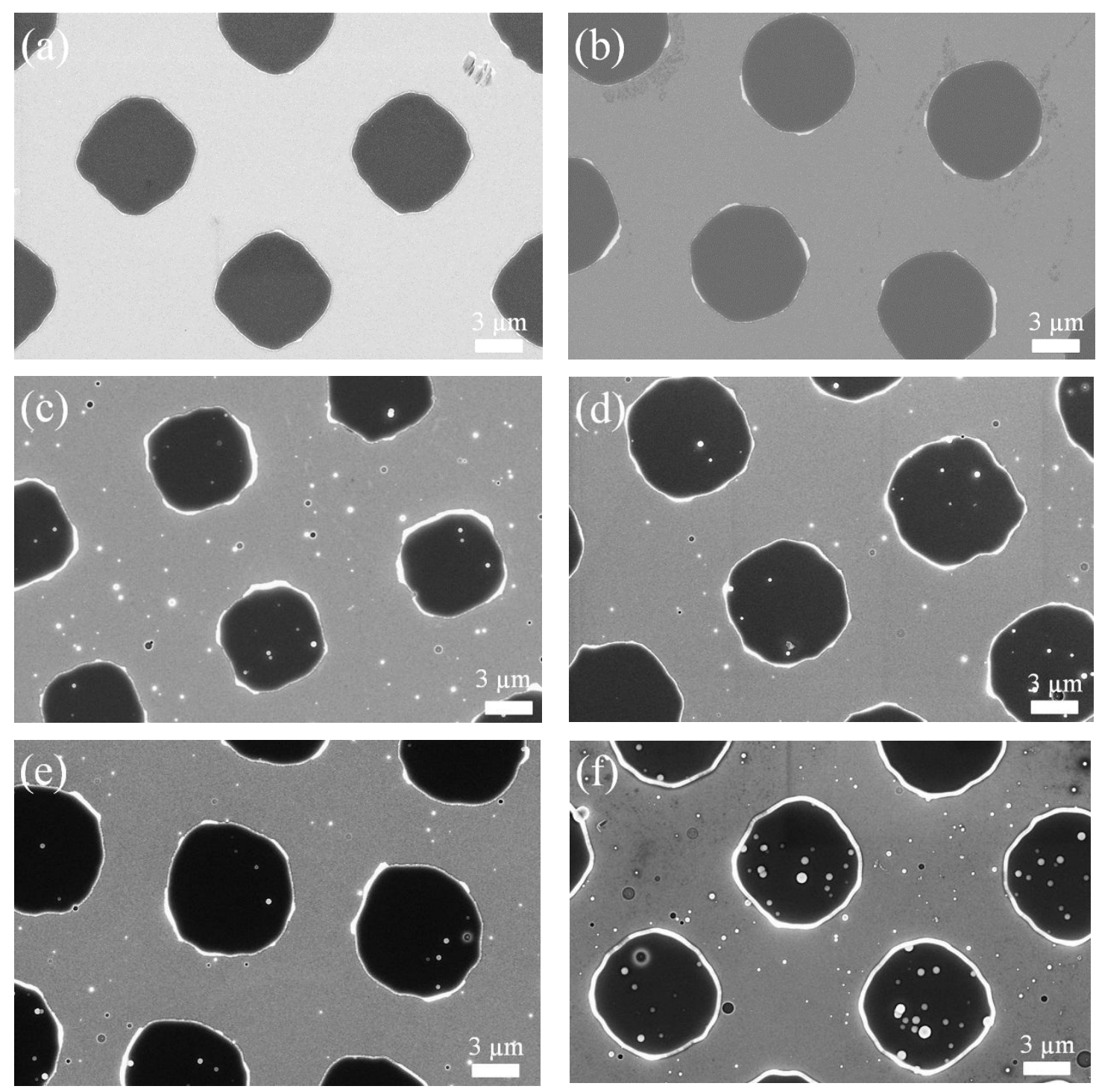

Figure 3. As-prepared patterned films with islands' height of $28 \mathrm{~nm}$ (a), $50 \mathrm{~nm}$ (b), $100 \mathrm{~nm}$ (c), $200 \mathrm{~nm}$ (d), $400 \mathrm{~nm}$ (e), $800 \mathrm{~nm}$ (f) 

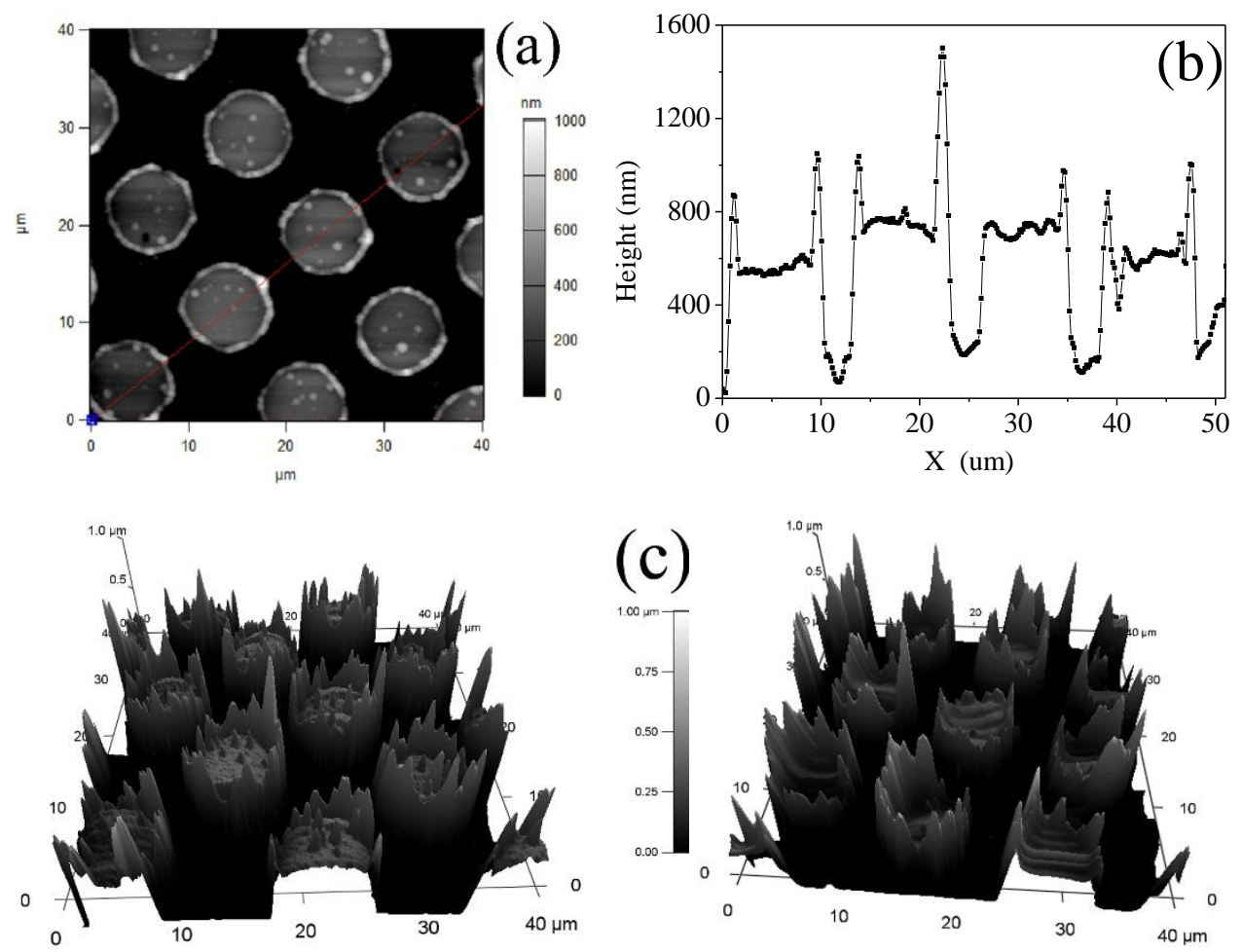

(d)

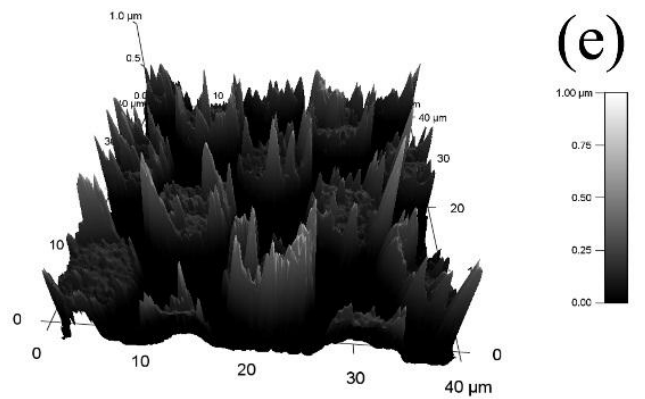

(e)

Figure 4. (a) AFM images and (b) cross sectional profile of $\mathrm{V}_{2} \mathrm{O}_{5}$ patterned film with the islands' height of $800 \mathrm{~nm}$; 3D image of the patterned film original (c), after plasma (d), after annealing (e). 


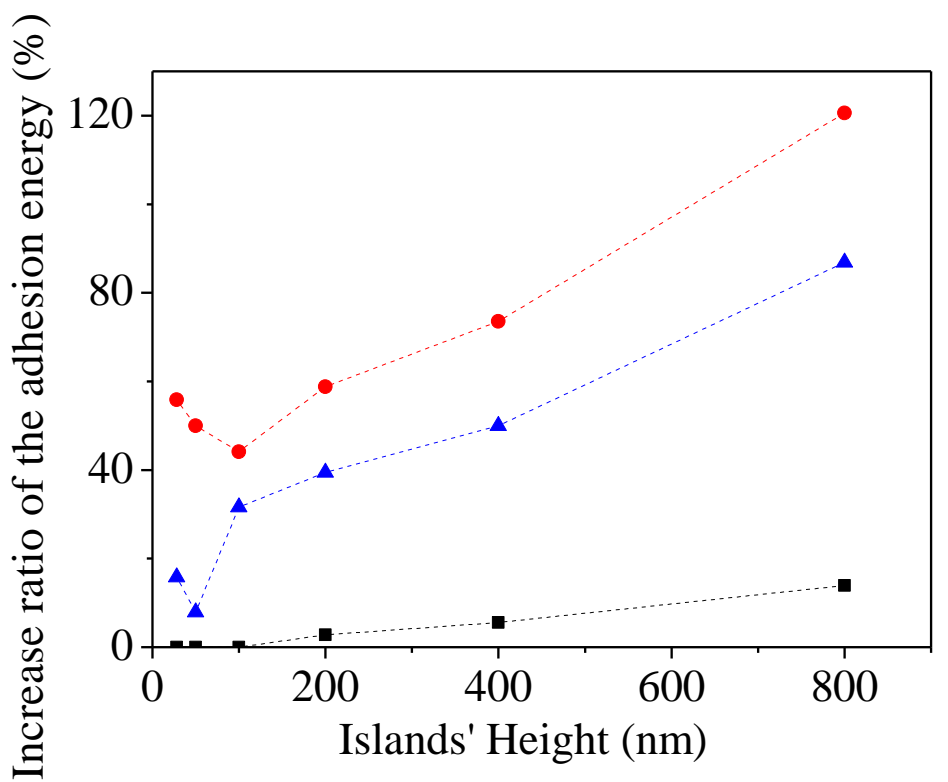

Figure 5 Increase ratio of the adhesion energy of PEO to the $\mathrm{V}_{2} \mathrm{O}_{5}$ patterned films with islands of a series heights (from $28 \mathrm{~nm}$ to $800 \mathrm{~nm}$ ) over the $\mathrm{V}_{2} \mathrm{O}_{5}$ smooth film due to roughness (red $\bullet$ after plasma) (blue $\boldsymbol{\Delta}$ after annealing) and due to the increase surface area(black $\mathbf{\square})$ 

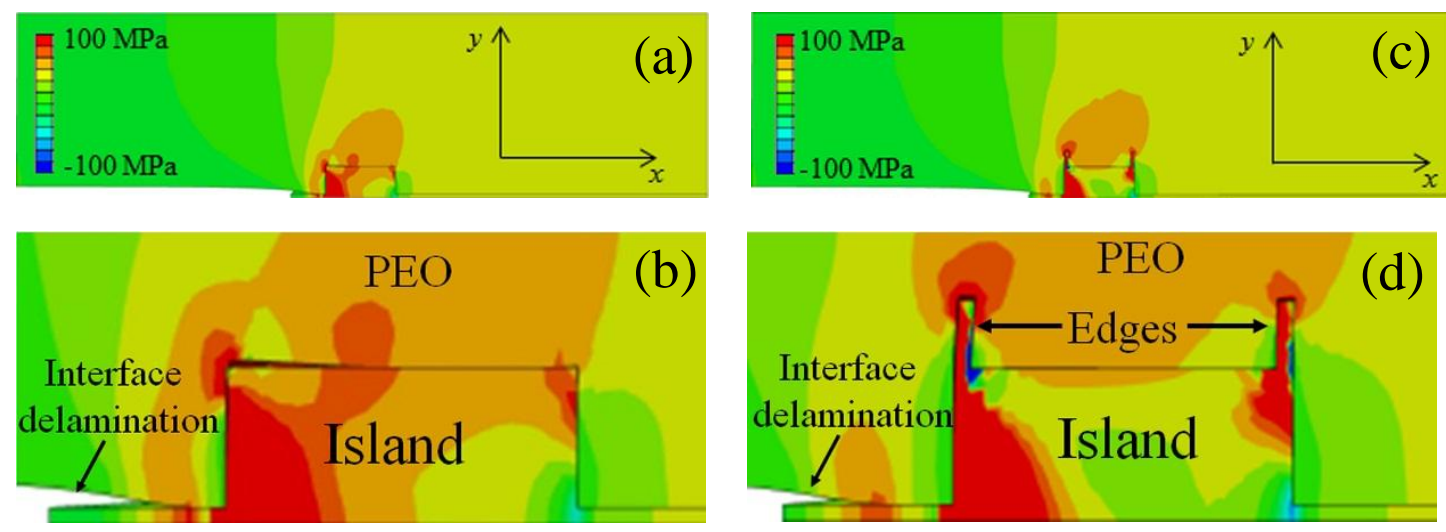

Figure 6. Numerical simulations for adhesion tests of PEO on $\mathrm{V}_{2} \mathrm{O}_{5}$ patterned films through finite element method (FEM) simulations with ABAQUS. (a) Stress $\left(\sigma_{\mathrm{yy}}\right)$ contours in PEO and $\mathrm{V}_{2} \mathrm{O}_{5}$ patterned film without edge at applied strain 0.043. (b) The zoom in island structure. (c) Stress $\left(\sigma_{\mathrm{yy}}\right)$ contours in PEO and $\mathrm{V}_{2} \mathrm{O}_{5}$ patterned film with edge at applied strain 0.043. (d) The zoom in island structure with edge. 
(a)

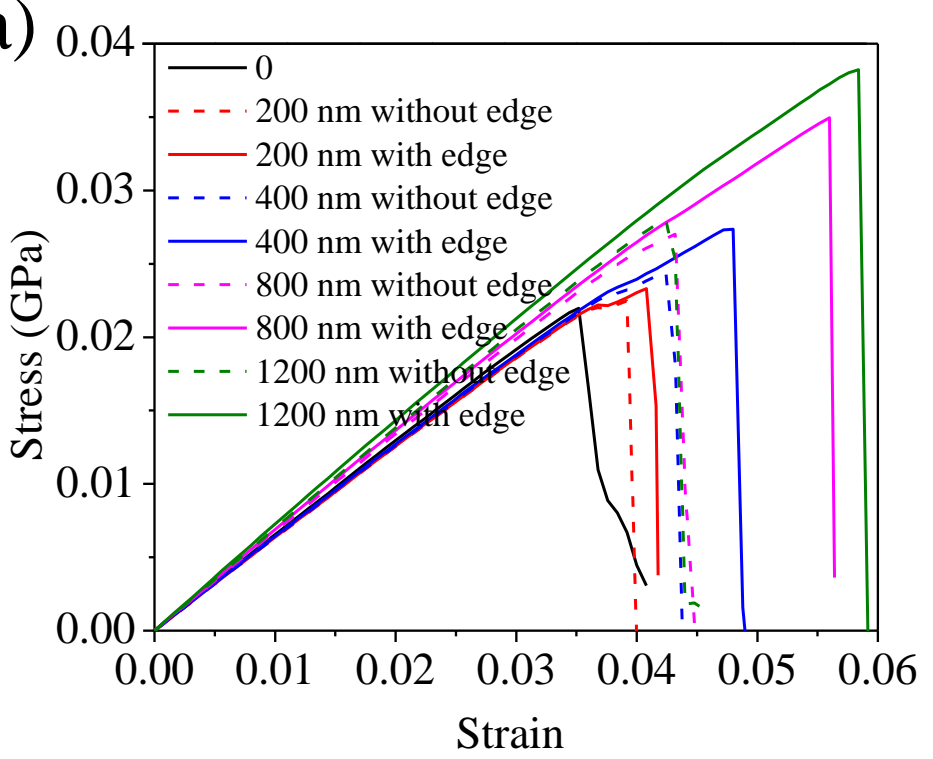

(b)

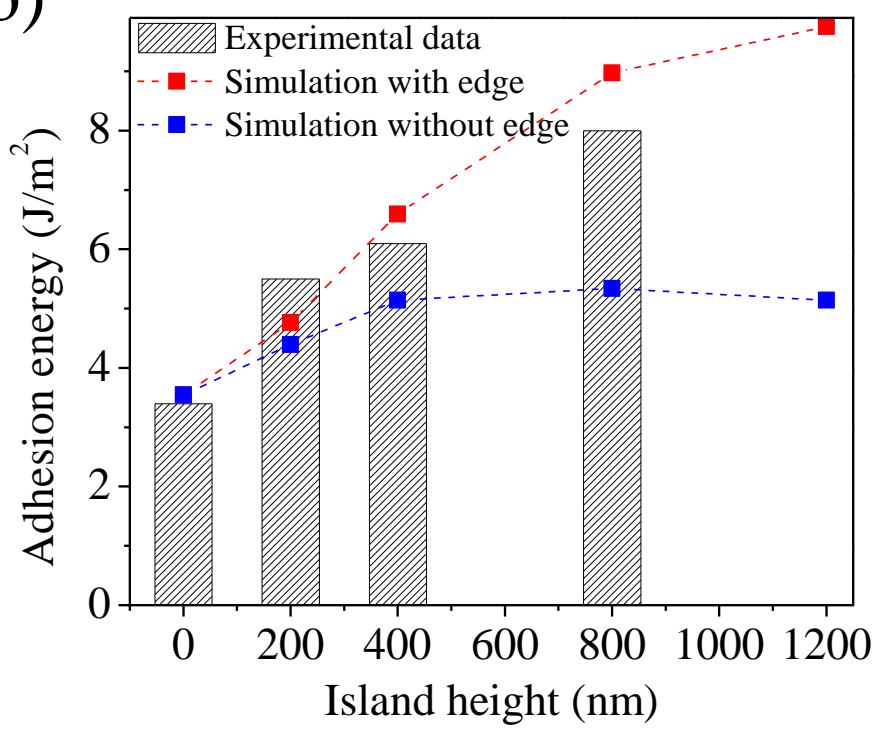

Figure 7 (a) Stress-strain curves for different island height. (b) Comparison of the adhesion energy between experiment and simulations. 
Table1. Adhesion energy of PEO electrolyte to various $\mathrm{V}_{2} \mathrm{O}_{5}$ smooth/patterned film before / after plasma treatment and annealing.

\begin{tabular}{|c|c|c|c|c|c|c|c|}
\hline Height (nm) & $\begin{array}{l}\text { Smooth } \\
\text { film }\end{array}$ & 28 & 50 & 100 & 200 & 400 & 800 \\
\hline Original $\left(\mathrm{J} / \mathrm{m}^{2}\right)$ & 3.2 & 11 & 15.7 & 14 & 13 & 13.6 & 28 \\
\hline $\begin{array}{l}\text { After plasma } \\
\text { treatment }\left(\mathrm{J} / \mathrm{m}^{2}\right)\end{array}$ & 3.4 & 5.3 & 5.1 & 4.9 & 5.5 & 6.1 & 8 \\
\hline $\begin{array}{l}\text { Increase due to } \\
\text { roughness }\end{array}$ & & 1.9 & 1.7 & 1.5 & 2 & 2.5 & 4.1 \\
\hline $\begin{array}{l}\text { Estimation based } \\
\text { on surface }\left(\mathrm{J} / \mathrm{m}^{2}\right)\end{array}$ & 3.4 & 3.4 & 3.4 & 3.4 & 3.5 & 3.6 & 3.9 \\
\hline $\begin{array}{l}\text { Increase due to the } \\
\text { surface area }\end{array}$ & 0 & 0 & 0 & 0 & 0.1 & 0.2 & 0.5 \\
\hline $\begin{array}{l}\text { After annealing } \\
\left(\mathrm{J} / \mathrm{m}^{2}\right)\end{array}$ & 3.8 & 4.4 & 4.1 & 5 & 5.4 & 5.9 & 7.6 \\
\hline $\begin{array}{l}\text { Increase due to } \\
\text { roughness }\end{array}$ & & 0.6 & 0.3 & 1.2 & 1.5 & 1.9 & 3.3 \\
\hline $\begin{array}{l}\text { Estimation based } \\
\text { on surface }\left(\mathrm{J} / \mathrm{m}^{2}\right)\end{array}$ & 3.8 & 3.8 & 3.8 & 3.8 & 3.9 & 4 & 4.4 \\
\hline $\begin{array}{l}\text { Increase due to the } \\
\text { surface area }\end{array}$ & 0 & 0 & 0 & 0 & 0.1 & 0.2 & 0.6 \\
\hline
\end{tabular}

